\title{
Effect of Omacor on HRV parameters in patients with recent uncomplicated myocardial infarction - A randomized, parallel group, double-blind, placebo-controlled trial: study design [ISRCTN75358739]
}

\author{
Cornel Pater*1, Daniele Compagnone ${ }^{3}$, Joachim Luszick ${ }^{1}$ and Cees- \\ Nico Verboom ${ }^{2}$
}

Address: ${ }^{1}$ Department of Cardiovascular Clinical Development, Solvay Pharmaceuticals GmbH, Hannover, Germany, ${ }^{2}$ Global Product Strategy Department, Solvay Pharmaceuticals GmbH, Hannover Germany and ${ }^{3}$ Department of Gastroenterology and Gynecology Clinical Development, Solvay Pharmaceuticals GmbH, Hannover, Germany

Email: Cornel Pater* - cornel.pater@solvay.com; Daniele Compagnone - daniele.compagnone@solvay.com; Joachim Luszick - joachim.luszick@solvay.com; Cees-Nico Verboom - cees-nico.verboom@solvay.com

* Corresponding author

Published: 15 October 2003

Current Controlled Trials in Cardiovascular Medicine 2003, 4:2
Received: 30 July 2003

Accepted: 15 October 2003

This article is available from: http://cvm.controlled-trials.com/content/4/I/2

(C) 2003 Pater et al; licensee BioMed Central Ltd. This is an Open Access article: verbatim copying and redistribution of this article are permitted in all media for any purpose, provided this notice is preserved along with the article's original URL.

\begin{abstract}
Background: A large body of data derived from animal, epidemiological and clinical studies indicate that n-3 polyunsaturated fatty acids have a favourable effect on the prognosis of patients with cardiovascular disease in general, and on reducing sudden death in particular.

Depressed heart rate variability (HRV), an indicator of impairment of the autonomic nervous system, has been shown to be a powerful predictor of subsequent mortality in patients surviving an acute myocardial infarction. A multitude of studies have demonstrated this strong association, suggesting that the imbalance in the sympathic/parasympathetic system may facilitate emergence of ventricular arrhythmias.

Heart rate variability parameters will be assessed in the present study, with the primary objective of evaluating the possible superiority of Omacor (a highly refined, concentrated omega-3 fatty acid) versus placebo in improving HRV from baseline to endpoint in patients with recent uncomplicated myocardial infarction. Both groups will receive optimal conventional treatment.

The study will also explore and quantify improvement in time domain HRV indices and will assess the safety of administering Omacor to optimally treated post-infarction patients (conventional treatment).

Methods: This multi-centre study will evaluate the effect of Omacor I g, o.d. on time-domain HRV parameters in comparison to placebo o.d. in patients with recent uncomplicated transmural myocardial infarction.

Patients will be screened during the first few days after the acute event as appropriate for the patient's condition, and after obtaining informed consent. Based on inclusion/exclusion criteria, a first 24-hour Holter recording will be performed. Two to five days later, screened patients still eligible for the study will undergo a second 24-hour Holter recording. After the second Holter
\end{abstract}


recording, all patients will be randomly allocated to treatment with Omacor I g, o.d. or placebo o.d.

One hundred patients will be followed in double-blind fashion for a six-month period after randomization. Visits, including 24-hour Holter recording and assessment of adverse events, will take place at one-month intervals \pm five days after randomization, i.e., six times in all.

\section{Background}

More than two decades ago, Bang and Dyerberg [1] insightfully suggested that the low mortality from cardiovascular disease among Greenland Eskimos could be due to the high concentration of $n-3$ polyunsaturated fatty acids (PUFA) in their diet, which is high in marine vertebrates. These observations triggered extensive studies that focused on the role of marine oils in preventing coronary heart disease [2-8] These studies began primarily in the 1980s, with ongoing efforts geared towards demonstrating that the biochemical and physiological effects of 3-n fatty acids might be beneficial in preventing/reducing atherosclerosis and depressive disorders through effects on the basic functions of neurons and by preventing cardiovascular arrhythmia through effects on the electrophysiology of cardiac myocytes $[9,10]$.

Results derived from laboratory animal studies [11-18], epidemiological and metabolic studies [19-25] as well as from clinical trials [26-32], provide evidence that PUFAs exert some form of basic control over cardiac and neural function, and that this has been largely overlooked, despite current dietary guidelines, which recommend fish consumption twice weekly for prevention of coronary heart disease (CHD) [33].

Results of the GISSI-Prevenzione study [34] (11,323 patients with recent myocardial infarction randomized to Omacor or vitamin $\mathrm{E}$ or the combination of the two) showed significantly lower all-cause mortality in the Omacor group, resulting largely from a $45 \%$ reduction in sudden cardiac death during 3.5 years of follow-up. Although the mechanism of action of Omacor is still unknown, the benefits appear to relate to reducing lethal arrhythmias rather than to changing cholesterol levels or to any anticoagulant effect.

With the enormous burden of sudden cardiac death that occurs virtually worldwide, and with cardiovascular disease poised to remain the number one killer in the world for at least the next 30 years, there may be substantial public health benefits to understanding PUFA's favourable health effects.

The present study will explore the potential effects of Omacor versus placebo on HRV through repeated assessment of a number of time domain HRV parameters and determination of plasma fatty acid concentrations in patients who have experienced a recent uncomplicated myocardial infarction.

\section{Methods \\ Patient Population}

HRV decreases in the early stages after an acute myocardial infarction [35-42] and spontaneously and slowly normalizes by the end of the first year $[43,44]$. Its assessment as early as possible after the acute event [45], at pre-discharge from the coronary care unit and on a monthly basis during the ensuing six months therefore is expected to predict further mortality [46].

In the context of the current study, it is expected that improvement in the HRV parameters of actively treated (as compared to placebo treated) patients will significantly diminish risk for arrhythmia-related sudden death.

Subjects will be recruited from the coronary care units of four tertiary hospitals in Poland and from four tertiary hospitals in Lithuania. The study is sponsored by Solvay Pharmaceuticals GmbH, Hannover, Germany and will be carried out in collaboration with Quantum Research, UK [47] and Scope International Life Sciences, Germany [48].

Potentially eligible patients with diagnosed acute myocardial infarction will be selected by the cardiologist in charge. Screening of these patients for the study will be performed during the first 48-72 hours after the acute event.

Subsequent to confirming eligibility and obtaining written consent, a first 24-hour Holter recording will be obtained and the following variables will be checked:

- Medical History

- Physical Examination

- BP and HR

- 12-lead ECG

- LVEF

- Troponin T/CK-MB (max values only) 


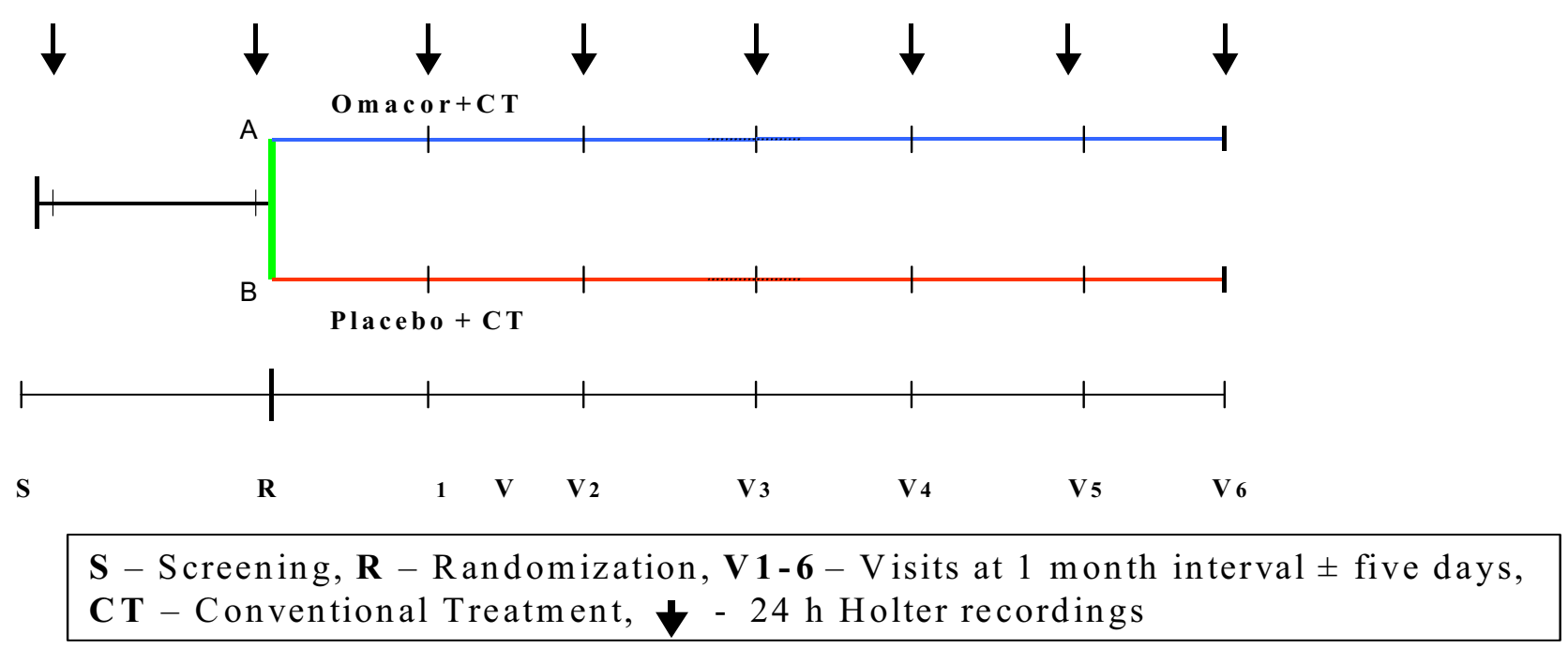

Figure I

Study Design.

- 24-hour Holter recording (HRV)

- Laboratory (blood sampling + urine)

- Current medication

Two to five days later, when the patient's clinical condition is deemed stable and the patient remains eligible for the study, a second 24-hour Holter recording is obtained. The next day, patients are randomly allocated to treatment with Omacor or placebo. The study flow diagram is noted in Fig. 1.

Planned investigations during the monthly visits are displayed in the Investigation Schedule (Table 1).

Apart from study treatment, patients will receive individualized optimal treatment. Post-myocardial infarction follow-up (secondary prevention) will be based on local medical care, to include dietary and physical activity advice.

\section{Randomization and Blinding}

The randomization list will be provided by the Department of Clinical Supplies at Solvay Pharmaceuticals BV with the program Almedica (Version 5.3). Patients will be allocated in equal numbers to each sequence. A fixed block size of patients will be used, and only complete blocks of study medication will be provided to the centres.
Within each centre, randomization numbers will be used in ascending order and patients will be allocated to randomization code numbers in chronological order.

The randomization code for study medication will be provided to the investigator in separate sealed envelopes labelled with study number and randomization code numbers. The process of randomization will be concealed.

\section{Inclusion Criteria}

Males and females aged 40 years or older, with recent sustained acute myocardial infarction (AMI) will be eligible for the study. Women of childbearing age will be subject to pregnancy testing and will agree to maintain adequate hormonal contraception.

Standard criteria for definition of acute, evolving or recent AMI as well as for established AMI will be applied in the patient screening process.

Signed informed consent is required before enrollment in the study can proceed.

\section{Exclusion Criteria}

Specific exclusion criteria detailed in the study protocol can be categorized into three groups:

1. Ineligibility based on the physician's decision (the cardiologist in charge) that the patient has a clinical or 
Table I: InvestigationSchedule

\begin{tabular}{|c|c|c|c|c|c|c|c|c|}
\hline & Screen & $\mathbf{R}$ & VI & V2 & V3 & V4 & V5 & V6 \\
\hline Informed Consent & $*$ & & & & & & & \\
\hline Incl/Excl Criteria & $*$ & $*$ & & & & & & \\
\hline Medical History & $*$ & & & & & & & \\
\hline Physical Exam & * & & & & * & & & $*$ \\
\hline $\mathrm{BP}$ and $\mathrm{HR}$ & * & $*$ & $*$ & $*$ & * & * & $*$ & $*$ \\
\hline ECG (12 lead) & $*$ & & & & $*$ & & & $*$ \\
\hline HRV & * & $*$ & $*$ & $*$ & $*$ & $*$ & $*$ & $*$ \\
\hline Lab & * & & & & * & & & $*$ \\
\hline Current medication & * & $*$ & $*$ & $*$ & $*$ & * & $*$ & $*$ \\
\hline \multicolumn{9}{|l|}{ ASA } \\
\hline \multicolumn{9}{|l|}{ Diuretic } \\
\hline \multicolumn{9}{|l|}{ Beta-blocker } \\
\hline \multicolumn{9}{|l|}{ Ca antagonist } \\
\hline \multicolumn{9}{|l|}{ ACE-inhibitor } \\
\hline \multicolumn{9}{|l|}{$\mathrm{Ag} \|$} \\
\hline \multicolumn{9}{|l|}{ Lipid lowering } \\
\hline \multicolumn{9}{|l|}{ Nitrates } \\
\hline Adverse Events & & $*$ & $*$ & $*$ & $*$ & $*$ & $*$ & $*$ \\
\hline Med. dispense & * & $*$ & $*$ & $*$ & $*$ & $*$ & $*$ & \\
\hline Med. collection & & $*$ & $*$ & $*$ & $*$ & $*$ & $*$ & $*$ \\
\hline
\end{tabular}

hemodynamically unstable condition, or based on the likelihood that the patient needs further invasive investigation, a PTCA or a CABG.

2. The patient is in need of sustained antiarrhythmic therapy (other than a beta-blocking agent administered in the context of secondary prevention of MI).

3. The patient is suffering from a severe concomitant illness (related to any body organ or system) that is likely to affect outcome assessment. Likewise, ineligibility will be declared for patients anticipated to have compliance problems, those participanting in another trial within the past 30 days, those who are pregnant or lactating, or who have a known hypersensitivity to the ingredients in Omacor or intolerability to olive oil. In addition, patients with diabetes mellitus type I and II will be excluded.

\section{Study Outcomes}

Prior and Concomitant Therapy

The study protocol calls for every patient to be treated optimally by the physician in charge and to receive comprehensive, individualized advice regarding relevant dietary and physical activity prior to discharge from the hospital. Visits are to be scheduled in the context of the study (monthly visits during the ensuing six months).

Antiarrhythmic therapy is not permitted during study involvement, except for the use of beta-blockers, since these drugs are prescribed in most patients with recent acute myocardial infarction (except for those with clear contraindications). Patients on anticoagulant treatment will undergo regular bleeding time checks according to local routines.

\section{Ethics and Informed Consent}

With reference to paragraph 29 in the latest version of The Declaration of Helsinki [49-52] (currently Declaration of Edinburgh, 2000), use of placebo in this particular trial is justified by the need to explore efficacy of the product under rigorous experimental conditions, as well as to explore the mechanism of action responsible for the favourable effect of the drug in the targeted population.

Written consent, involving provision of detailed information regarding the study objectives, design, scope of the intervention, risks and benefits, will be obtained for all patients before intiating any study procedures.

Likewise, study documentation is to be subject to the scrutiny of local ethical committees in the two countries participating in the study.

\section{Sample Size and Statistical Analysis}

For the primary efficacy variable, the change in (standard deviation of all NN intervals (SDNN) from baseline to six months (or last value in case of dropouts), a normal distribution with a standard deviation of $\sigma=50 \mathrm{~ms}$ is assumed. If a two-sided two sample t-test with a level of significance of $\alpha=0.05$ is applied, 45 patients per treat- 
Table 2: Time Domain HRV Parameters

\begin{tabular}{|c|c|}
\hline Time-domain indices & Description \\
\hline Mean RR interval & The average $\mathrm{NN}$ interval per hour; a single 24 hour average will be reported. \\
\hline SDNN & Standard deviation of the NN interval every hour; a single 24-hour average will be reported. \\
\hline SDNNi & Standard deviation of the $\mathrm{NN}$ interval in every 5 minutes; a single 24 -hour average will be reported. \\
\hline RMSSD & The root mean square of successive differences of adjacent $N N$ intervals; a single 24 -hour average will be reported. \\
\hline sNN50 & $\begin{array}{l}\text { Number of pairs of adjacent NN intervals differing by }>50 \mathrm{~ms} \text {; a single } 24 \text {-hour value for the increases, decreases and } \\
\text { total will be reported. }\end{array}$ \\
\hline Triangular Index & $\begin{array}{l}\text { Total number of all NN intervals divided by the height of the histogram of all NN intervals measured on a discrete scale } \\
\text { with bins of I/I28s; a single 24-hour average will be reported. }\end{array}$ \\
\hline sNN6\% & $\begin{array}{l}\text { Number of pairs of adjacent } N N \text { intervals differing by }>6 \% \text {; a single } 24 \text {-hour value for the increases, decreases and total } \\
\text { will be reported. }\end{array}$ \\
\hline VPC > $10 \% /$ hour & $\begin{array}{l}\text { The number of hourly segments with > } 10 \% \text { SVE and VPCs will be reported and the absolute number of SVE and VPCs } \\
\text { will also be reported. }\end{array}$ \\
\hline
\end{tabular}

ment group will be needed to achieve $80 \%$ statistical power and to detect a mean difference of $\Delta=30 \mathrm{~ms}$ between the treatment groups. One hundred patients will be randomized.

For the primary efficacy parameter, the null hypothesis of equal treatment group means will be tested against the two-sided alternative of different treatment group means at a level of significance of $\alpha=0.05$. For this, an analysis of covariance (ANCOVA) model will be applied, to include the treatment group and the medical center as factors and the baseline SDNN as a covariate.

In addition to the analysis of the total patient population, the following subgroups of patients will be evaluated in an exploratory fashion (the definition of these categories may be changed during blind data review):

- Mildly decreased or normal HRV: SDNN > 100 ms

- Moderately decreased HRV: SDNN between $50 \mathrm{~ms}$ and $100 \mathrm{~ms}$ (inclusive)

- Severely decreased HRV: SDNN < $50 \mathrm{~ms}$

Analysis of secondary efficacy parameters and analysis of safety will be descriptive and exploratory.

\section{Time Domain HRV Indices}

The effect of treatment on time domain HRV parameters will be assessed by comparing a number of parameters derived from 24-hour Holter recordings. Time domain indices that are to be assessed and analysed are displayed in Table 2.

The SDNN and the HRV Triangular Index are estimates of the overall HRV. SDNN estimates the long-term components of the HRV, while the RMSSD estimates the short- term components of the HRV. The sNN50 and 6\% family parameters provide useful information about the very short term control of sinus rhythm dynamics in both healthy and diseased individuals, related to parasympathetic regulation.

The 24-hour Holter recordings will be analyzed using the Lifecard CF system produced by Reynolds Medical, UK [53]. A recording that cannot provide a minimum of 18 hours of data (including the whole night) out of the 24 hour Holter recording will be excluded from the analysis.

\section{The Lifecard CF System [53]}

The Lifecard CF is a compact Holter Ambulatory ECG Recorder utilizing a digital storage technique to store the ECG recording onto a Compact Flash (CF) card.

The Lifecard CF is small and lightweight and provides continuous recording of 2 or 3 channels of ECG. It has a built in display that enables one to monitor the ECG and pacing detection during hook-up. This enables one to verify the ECG quality before starting recording

Recordings are to be analyzed on the Reynolds Medical Pathfinder Digital/700 Series Analysis System, fitted with the appropriate Flashcard reader and will be performed by highly trained analysts from Quantum Research, UK.

A study specific Instruction Manual for use of Holter devices (including patient's hook-up) will be provided to every investigative site.

\section{Discussion}

In patients who have experienced an MI, depressed heart rate variability is considered to be a powerful predictor of mortality and of arrhythmic complications (e.g., symptomatic sustained ventricular tachycardia). [8,54]. The predictive value of HRV is independent of other factors 
established for post-infarction risk stratification, such as depressed left ventricular ejection fraction, increased ventricular ectopic activity, and presence of late potential. For prediction of all-cause mortality, the value of HRV is similar to that of left ventricular ejection fraction, but HRV is superior to left ventricular ejection fraction in predicting arrhythmic events (sudden cardiac death and ventricular tachycardia) [54]. This suggests that HRV is a stronger predictor of arrhythmic (as opposed to non-arrhythmic) mortality.

The present study is not powered to detect differences in clinical endpoints, in particular sudden death. However, subgroup analysis will be performed in an attempt to reveal eventual differences in HRV between sudden and non-sudden cardiac death. It is not yet established whether depressed HRV is part of the mechanism of increased post-infarction mortality or is merely a marker of poor prognosis. Available data suggest that depressed HRV is not a simple reflection of sympathetic overdrive and/or vagal withdrawal due to poor ventricular performance but that it also reflects depressed vagal activity, which has a strong association with the pathogenesis of ventricular arrhythmias and sudden cardiac death [55]. A stratification of patients on the basis of LVEF is not realistic, given the small sample size; however, recording of LVEF in all patients will allow for an exploratory analysis and hypothesis generation.

\section{Conclusions}

Available evidence suggests that Omacor may provide benefit in the immediate post-myocardial infarction period. The present study will evaluate whether EPA and DHA, which constitute $84 \%$ of the Omacor tablet, improve time domain HRV parameters and surrogates for arrhythmia-caused sudden death in post-myocardial infarction patients.

\section{Abbreviations}

$\Delta$ difference

AE adverse event

ALAT alanine aminotranspherase

AMI acute myocardial infarction

ASAT aspartate aminotranspherase

AV atrioventricular

BP blood pressure

$\mathrm{Ca}^{2+}$ calcium ions
CCU coronary care unit

CK-MB creatine kinase - isoenzyme MB

CPT-I carnitine palmitoyltransferase I

CHD coronary heart disease

CRF case report form

DHA docosahexaenoic acid

ECG electrocardiogram

EPA eicosapentaenoic acid

FAT fatty acid transporter

GCP good clinical practice

GISSI Gruppo Italiano per lo Studio della Soprawivenza nell'Infarto miocardico

HR heart rate

HRV heart rate variability

ICH International Conference on Harmonization

$\mathrm{K}_{\mathrm{I}}$ inhibition constant

$\mathrm{K}^{+}$potassium ion

LBBB left bundle branch block

LVEDP left ventricular end diastolic pressure

LVESP left ventricular end systolic pressure

LVEF left ventricular ejection fraction

MI myocardial infarction

mRNA messenger RNA (carriers genetic information for one single protein)

ms milliseconds

$\mathrm{n}, \mathrm{N}$ number of patients

$\mathrm{Na}^{+}$sodium ion

o.d. once daily 
Q wave negative deflection on the ECG occuring before the QRS complex

QRS "complex" - depolarisation on ECG

p probability ( $5 \%$ alpha level)

p.o. per oral

PUFA polyunsaturated fatty acids

RBBB right bundle branch block

$\mathrm{R}$ wave positive deflection on ECG

RAAS rennin-angiotensin-aldosterone system

RMSSD the square root of the mean of the sum of the segments of differences

between adjacent $\mathrm{NN}$ intervals

RR average NN interval, per hour and 24 hour average

SAE serious adverse event

sNN50 number of adjacent $\mathrm{NN}$ intervals differing by $>50$ $\mathrm{ms}$

sNN6\% number of pairs of adjacent NN intervals differing by $>6 \%$

SDNN standard deviation of all NN intervals

SDANN standard deviation of the averages of NN intervals in all 5 minutes

segments

SDNNi mean of the standard deviations of all NN intervals for all 5 minutes

segments

ST "segment" - repolarisation phase on ECG

T troponine $\mathrm{T}$

Triangular total number of all NN intervals devided by the hight of the histogram of

\section{all NN}

Index intervals measured on a discrete scale with bins of $1 / 128 s$
VPB ventricular premature beats

WHO World Health Organisation

\section{Competing interests}

All authors are employed by Solvay Pharmaceuticals GmbH Hannover, Germany.

\section{Authors' contributions}

Study concept and design: Pater, Verboom, Luszick,

Drafting of manuscript: Pater

Statistical expertise: Compagnone

\section{References}

I. Dyrberg J and Bang HO: Haemostatic function and platelet polyunsaturated fatty acids in Eskimos. Nutrition 1995, II (5):475-6.

2. Kang JX and Leaf A: Prevention of fatal cardiac arrhythmias by polyunsaturated fatty acids. Am J Clin Nutr 2000, 7 I:202S-7S.

3. Burr ML, Fehily AM and Gilbert JF et al.: Effect of changes in fat, fish, and fibre intakes on death and myocardial reinfarction: diet and reinfarction trial(DART). Lancet 1989, 2:757-6I.

4. de Lorgeril $M$, Renaud $S$ and Mamelle $\mathrm{N}$ et al:: Mediterranean alpha-linoleic acid-rich diet in secondary prevention of coronary heart disease. Lancet 1994, 343: 1454-9.

5. Siscovick DS, Raghunathan TE and King I et al.: Dietary intake and cell membrane levels of long-chain n-3 polyunsaturated fatty acids and risk of primary cardiac arrest. JAMA 1995, 274: I363-7.

6. Singh RB, Niaz MA, Sharma JP, Kumar R, Rastogi $V$ and Moshiri M: Randomized, double-blind, placebo-controlled trial of fish oil and mustard oil in patients with suspected acute myocardial infarction: the Indian experiment of infarct survival-4. Cardiovasc Drugs Ther 1997, I 1:485-91.

7. Christensen $\mathrm{JH}$, Korup $\mathrm{E}$ and Aaroe $\mathrm{J}$ et al.: Fish consumption, $\mathbf{n}-\mathbf{3}$ fatty acids in cell membranes, and heart variability in survivors of myocardial infarction with left ventricular dysfunction. Am J Cardiol 1997, 79:1670-3.

8. Albert CM, Hennekens $C O$ and O'Donnel $C J$ et al:: Fish consumption and risk of sudden death. JAMA 1998, 279:23-8.

9. McLennan PL, Bridle TM, Abeywardena MY and Charnock JS: Comparative efficacy of $n-3$ and $n-6$ polyunsaturated fatty acids in modulating ventricular fibrillation threshold in marmoset monkeys. Am J Nutr 1993, 58(5):666-9.

10. Kris-Etherton PM, Harris WS and Appel LJ et al.: Fish consumption, fish oil, omega-3 fatty acids and cardiovascular disease. Circulation 2002, 106:2747-2757.

II. van Bilsen M, van der Vusse GJ, Willemsen PH, Coumans WA, Roemen TH and Reneman RS: Lipid alterations in isolated, working rat hearts during ischaemia and reperfusion: its relation to myocardial damage. Circ Res 1989, 64:304-14.

12. Chien KR, Han A, Sen A, Buja LM and Willerson JT: Accumulation of unesterified arachidonic acid in ischemic canine myocardium. Relationship to a phosphatidylcholine deacylation-reacylation cycle and the depletion and the depletion of membrane phospholipids. Circ Res 1984, 54:313-22.

13. Corr PB, Cain ME, Witkowski FX, Price DA and Sobel BE: Potential arrhythmogenic electrophysiological derangements in canine Purkinje fibers induced by lysophosphoglycerides. Circ Res 1979, 44:822-32.

14. Magishi K, Kimura J, Kubo $Y$ and Abiko Y: Exogenous lysophosphatidylcholine increases non-selective cation current in guinea-pig ventricular myocytes. Pflugers Arch 1996, 432:345-50.

15. Xiao YF, Kang JX, Morgan JP and Leaf A: Blocking effects of polyunsaturated fatty acids on $\mathrm{Na}^{+}$channels of neonatal rat ventricular myocytes. Proc Natl Acad Sci 1995, 92: I 1000-4.

16. Power GWNE: Dietary fatty acids influence the activity and metabolic control of mitochondrial carnitine palmitoyltrans- 
ferase I in rat heart and skeletal muscle. I Nutr 1997, 127:2| 42-50.

17. van Bilsen M, de Vries JE and van der Vusse GJ: Long-term effects of fatty acids on cell viability and gene expression on neonatal cardiac myocytes. Prostaglandins Leukot Essen Fatty Acids 1997, 57:39-45.

18. van der Lee KA, Vork MM and De Vries JE et al.: Long-chain fatty acid-induced changes in gene expression in neonatal cardiac myocytes. J Lipid Res 2000, 4I:4I-7.

19. De Windt LJ, Reneman RS, van der Vusse GJ and van Bilsen M: Phospholipase A2-mediated hydrolysis of cardiac phosholipids: the use of molecular and transgenic technique. Mol Cell Biochem 1998, 180:65-73.

20. van Bilsen $M$ and van der Vusse GJ: Phospholipase-A2-dependent signaling in the heart. Cardiovasc Res 1995, 30:518-29.

21. van Bilsen M, van der Vusse G], Willemsen PH, Coumans WA, Roeman TH and Reneman RS: Effects of nicotinic acid and mepacrine on fatty acid accumulation and myocardial damage during ischemia and reperfusion. J Mol Cell Cardiol 1990, 22:155-63.

22. der Vusse G]: Phospholipid degradation in energy-deprived cardiac myocytes: does annexin $\mathbf{V}$ play a role? J Moll Cell Cardiol 1997, 29:1401-10

23. van der Vusse GJ, van Bilsen M and Reneman RS: Ischemia and reperfusion induced alterations in membrane phospholipids: an overview. Am NY Acad Sci 1994, 723: I- I4.

24. DaTorre SD, Creer MH, Pogwizd SM and Corr PB: Amphipathic lipid metabolites and their realtion to arrhythmogenesis in the ischemic heart. J Mol Cell Cardiol I99I, 23(Suppl I): I I-22.

25. Undrovinas Al, Fleidervish IA and Makielski JC: Inward sodium current at resting potentials in single cardiac myocytes induced by the ischemic metabolite lysophosphatidylcholine. Circ Res 1992, 7I: $\mid 231-41$.

26. Kang JX and Leaf A: Prevention of fatal cardiac arrhythmias by polyunsaturated fatty acids. Am J Clin Nutr 2000, 7 I:202S-7S.

27. Burr ML, Fehily AM and Gilbert JF et al.: Effect of changes in fat, fish, and fibre intakes on death and myocardial reinfarction: diet and reinfarction trial(DART). Lancet 1989, 2:757-6I.

28. de Lorgeril M, Renaud $\mathrm{S}$ and Mamelle $\mathrm{N}$ et al: Mediterranean alpha-linoleic acid-rich diet in secondary prevention of coronary heart disease. Lancet 1994, 343:1454-9.

29. Siscovick DS, Raghunathan TE and King I et al.: Dietary intake and cell membrane levels of long-chain n-3 polyunsaturated fatty acids and risk of primary cardiac arrest. JAMA 1995, 274: I 363-7.

30. Singh RB, Niaz MA, Sharma JP, Kumar R, Rastogi V and Moshiri M: Randomized, double-blind, placebo-controlled trial of fish oil and mustard oil in patients with suspected acute myocardial infarction: the Indian experiment of infarct survival-4. Cardiovasc Drugs Ther 1997, I I:485-91.

31. Christensen JH, Korup E and Aaroe J et al.: Fish consumption, n-3 fatty acids in cell membranes, and heart variability in survivors of myocardial infarction with left ventricular dysfunction. Am J Cardiol 1997, 79:1670-3.

32. Albert CM, Hennekens $C O$ and $O$ 'Donnel $C J$ et al.: Fish consumption and risk of sudden death. JAMA 1998, 279:23-8.

33. Rhodes KS, Bookstein LC and Aaronson LS et al: Intensive nutrition counselling enhances outcomes of National Cholesterol Education Program dietary therapy. I Am Diet Assoc 1996, 96:1003-1010

34. Marchioli R, Schweiger C, Tavazzi $L$ and Valaguassa F: Efficay of $\mathbf{n}-\mathbf{3}$ fatty acids after myocardial infarction; results of GISSI-Prevenzione trial. Lipids 200I, 36(Suppl):SI I9-26.

35. Kleiger RE, Miller JP, Bigger JT and Moss AJ: The Multicenter Postinfarction Research Group. Decreased heart rate variability and its association with increased mortality after acute myocardial infarction. Am J Cardiol 1987, 59:256-262.

36. Malik M, Farrel T, Cripps T and Camm AJ: Heart rate variability in relation to prognosis after myocardial infarction: selection of optimal processing techniques. Eur Heart J 1989, 10:1060-1074.

37. Farell TG, Bashir Y, Cripps T, Malik M, Poloniecki J, Bennett ED, Ward DE and Camm AJ: Risk stratification for arrhythmic events in postinfarctpatients based on heart rate variability, ambulatory electrocardiographic variables and the signalaveraged electrocardiogram. J Am Coll Cardiol I99I, 18:687-697.

38. Hartikainen JEK, Malik M, Staunton A and Camm A): Distinction between arrhythmic and non-arrhythmic death after acute myocardial infarction based on heart rate variability, signalaveraged electrocardiogram, ventricular arrhythmias and left ventricular ejection fraction. J Am Coll Cardiol 1995, 28:296-304.

39. Zuanetti G, Neilson JMM, Latini R, Santoro E, Maggioni AP, Ewing DJ and on behalf of GISSI-2 investigators: Prognostic significance of heart rate variability in post-myocardial infarction patients in the fibrinolytic era. The GISSI-2 results. Circulation 1996, 94:432-436.

40. Bigger JT, Fleis JL, Steinman RC, Rolnitzky LM, Kleiger RE and Rottman JN: Frequency-domain measures of heart period variability and mortality after myocardial infarction. Circulation 1992, 85:|64-|7|.

4I. ECG Substudy Investigators: Heart rate variability assessment early after acute myocardial infarction. Patophysiological and prognostic correlates. Circulation 1996, 93:1388-1395.

42. Quintana M, Storck N, Lindblad LE, Lindwall K and Ericson M: Heart rate variability as a means of assessing prognosis after acute myocardial infarction. Eur Heart J 1997, I 8:789-797.

43. Lombardi F, Sandrone $G$ and Mortara A et al.: Circadian variation of spectral indices of heart rate variability after myocardial infarction. Am Heart J 1992, 1 23:1521-9.

44. Bigger JT, Kleiger RT, Fleis JL, Rolnizky RM, Steinman RC, Miller JP and and the Multicenter Post-Infarction Research Group: Componenets of heart rate variability measured during healing of acute myocardial infarction. Am / Cardiol 1988, 6I:208-I5.

45. Casolo GC, Stroder P and Signorini $C$ et al.: Heart Rate Variability during the acute phase of myocardial infarction. Circulation 1992, 85:2073-9.

46. Bigger JT, Fleiss JL, Rolnitzky LM and Steinman RC: Frequency domain measures of heart period variability to assess risk late after myocardial infarction. J Am Coll Cardiol 1993, 21:729-36.

47. [http://www.quantum.ferrarisgroup.com]

48. [http://www.scope-clinical.com].

49. Bland JM and Kerr D: Fifth revision of Declaration of Helsinki. BM 2002, 324:975-975

50. Committee for Proprietary Medicinal Products (CPMP): Note for guidance on clinical investigation of medicinal products in the treatment of hypertension 1998. CPMP/EWP/238/95 Rev. I

51. Weber MA: The ethics of using placebo in hypertension clinical trials. Journal of Hypertension 1999, 17:5-8.

52. World Medical Association: World Medical Association Declaration of Helsinki: ethical principles for medical research involving human subjects 2000 [http://www.wma.net/e/policy/63.html]. Forney-Voltaire: WMA

53. [http://reynoldsmedical.com/]

54. Odemuyiwa O, Malik M, Farell T, Bashir Y, Poloniecki J and Camm J: Comparison of the predictive characteristics of Herat rate variability index and left ventricular ejection fraction for allcause mortality, arrhythmic events and sudden death alter acute myocardial infarction. Am J Cardiol I991, 68:434-9.

55. De Ferrari GM, Vanoli E and Schwartz PJ: Cardiac vagal acitvity, myocardial ishemia and sudden death. In: Cardiac electrophysiology. From cell to bedside Edited by: Zipes DP, Jalife J. Philadeplphia: W.B. Saunders; 1995:422-34.

Publish with BioMed Central and every scientist can read your work free of charge

"BioMed Central will be the most significant development for disseminating the results of biomedical research in our lifetime."

Sir Paul Nurse, Cancer Research UK

Your research papers will be:

- available free of charge to the entire biomedical community

- peer reviewed and published immediately upon acceptance

- cited in PubMed and archived on PubMed Central

- yours - you keep the copyright
BioMedcentral 